\title{
Hippocampal lesions and activity'
}

Robert J. Douglas and Robert L. Isaaeson UNIVERSITY OF MICHIGAN

\section{Abstract}

Rats with hippocampal damage, neocortical damage, and unoperated controls were given three tests of spontaneous activity. Hippocampal destruction was produced either by aspiration or electrolytic fulguration. Both hippocampally damaged groups spontaneously alternated at only "chance rates." Both were more active in exploration, but the aspiration group failed to display the normal decrements over time. The electrolytic hippocampals ran more in the exercise wheel, while the aspiration hippocampals ran less.

\section{Introduction}

The present experiment was undertaken to expand investigations of the role of the hippocampus in "spontaneous" (unrewarded) activity. Three different measures were used: spontaneous alternation in a $\mathrm{T}$ maze, exploration of a strange cage, and running in the exercise wheel. Reports on the effects of hippocampal lesions on activity in these situations already exist in the literature, but there is great variability between the studies in the location, type, and extent of lesions, as well as in general procedures. In the present study all animals were used in every task, and two methods of hippocampal destruction were employed.

\section{Apparatus}

Spontaneous alternation. An enclosed T maze of the usual size and contruction was used, with illumination provided by a $71 / 2 \mathrm{w}$ light placed over the choice point.

Activity cages. Three wire mesh cages measuring $11 \mathrm{x}$ 18 in and 11 in high were bisected on their longer axis by a photocell beam, interruptions of which were continuously recorded. The cages were used simultaneously in a darkened room.

Exercise wheels. Three exercise wheels of 12 1/2-in diameter with 5 1/2-in wide tracks were used in a dark room. Each wheel turn was automatically recorded.

\section{Method}

Subjects. One year old male hooded rats were divided into four groups with nearly equal mean body weights: aspiration hippocampals (Asp. Hip., $\mathrm{N}=11$ ), electrolytic hippocampals (Elec. Hip., $\mathrm{N}=4$ ), neocortical controls (Neocort., $\mathrm{N}=10$ ), and unoperated controls (Normals, $\mathrm{N}=12$ ). All were housed in individual cages with food and water provided ad libitum.

Surgery and histological evaluation. Both the Asp. Hip. and Neocort. groups had the neocortex overlying the lateral ventricle removed. In addition, Ss of the Asp. Hip. group suffered radical bilateral hippocampectomies by aspiration. Surgical procedures and histological evalations were similar to those reported elsewhere (Isaacson et al., 1961). The median value of hippocampal destruction was approximately $70 \%$. Neocortical damage was always more extensive in the Neocort. group

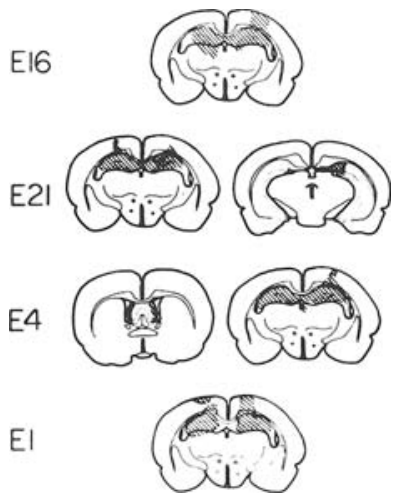

Fig. 1. Reconstructions of electrolytic hippocampal lesions.

than in the Asp. Hip. group. Bilateral electrolytic lesions of the dorsal hippocampus were produced by passing a $1.5 \mathrm{ma}$ current for $45 \mathrm{sec}$. Electrode placement was $2 \mathrm{~mm}$ posterior to bregma, $2 \mathrm{~mm}$ lateral from the midline, and $3 \mathrm{~mm}$ below the cortical surface. Reconstructions of these lesions are shown in Fig 1. Procedure. Preoperatively, all Ss were given two consecutive free trials in the $\mathrm{T}$ maze for five days as a test of spontaneous alternation. Two weeks postoperatively Ss were re-tested in the same manner for 10 days. One week later each $\mathrm{S}$ was tested for $1 \mathrm{hr}$. in the activity cage, and one week after this they were placed in the exercise wheel for $1 \mathrm{hr}$.

\section{Results and Discussion}

Spontaneous alternation. Postoperatively, alternation rates for all lesion groups were significantly lower than either their preoperative rates or the comparable rate of the unoperated Ss ( $P<.05$ or less for all t tests). Both hippocampal groups alternated less than the Neocort. group postoperatively ( $\mathrm{P}<.01$ for both tests), and were close to a $50 \%$ "chance level" of alternation (see Table 1). These results replicate those of Roberts et al. (1962). The data were analyzed for evidence of response bias and two Asp. Hip. Ss were found to have turned in only one direction. Their records are not included above or in the following results.

Activity cage. The mean numbers of photocell beam interruptions per hour are shown in Table 1. Both hippocampal groups were significantly more active than either of the other two groups ( $\mathrm{P}<.01$ for all $t$ tests). However, patterns of activity within the $1-\mathrm{hr}$. periods were different for the hippocampal groups, as is shown in Fig 2. Analysis of the shapes of these curves revealed that the time decrements for all groups except the Asp. Hip. group were significantly nonlinear $(\mathrm{P}<.01$ for all tests) and did not differ from each other. The curve of the Asp. Hip. group was close to linearity, and was different in 
Table 1. Summary of Results for all Three Tests of Spontaneous Activity.

Asp. Hip.: Ss with extensive hippocampal destruction by aspiration;

Elec. Hip.: Ss with electrolytic lesions of dorsal hippocampus;

Neocort.: Ss with neocortical destruction.

\begin{tabular}{|c|c|c|c|c|c|}
\hline \multirow[t]{2}{*}{ Group } & \multirow[t]{2}{*}{$\mathrm{n}$} & \multicolumn{2}{|c|}{ Alternation rate } & \multirow{2}{*}{$\begin{array}{c}\text { cage exploration } \\
\text { (no. beam breaks/hr.) }\end{array}$} & \multirow{2}{*}{$\begin{array}{l}\text { Exercise wheel } \\
(\text { no. rev•/hr.) }\end{array}$} \\
\hline & & Pre op. & Post op. & & \\
\hline Asp. Hip. & 9 & 97.8 & 53.3 & 295.9 & 88.6 \\
\hline Elec. Hip. & 4 & 85.0 & 57.5 & 269.3 & 172.3 \\
\hline Neocort. & 10 & 92.0 & 76.0 & 163.7 & 97.3 \\
\hline Normals & 12 & 88.8 & 89.2 & $152.9(n=8)$ & 121.8 \\
\hline
\end{tabular}

shape from all of the others $(\mathrm{P}<.05$ or less for all tests). This lack of a normal time decrement in the Asp. Hip. group is similar to that reported by Roberts et al. (1962) and by Teitelbaum \& Milner (1963).

Exercise wheel. The mean numbers of revolutions per hour are shown in Table 1 , and cumulative activity curves presented in Fig 3. The Elec. Hip. group was significantly more active in the wheel than were the Asp. Hip. or Neocort. groups ( $P<.05$ for both $t$ tests). No other differences approached significance except that between Elec. Hip. and Normal groups which reached the $10 \%$ level. None of the curves differed significantly in slope from the others. The failure to find a difference between the Asp. Hip. and Neocort. groups is similar to the earlier reports of Rasmussen et al. (1960) and Kaada et al. (1961).

\section{Conclusions}

This experiment has demonstrated that the occurrence of increased activity in hippocampally ablated rats depends upon (1) the method of measuring activity, and (2) the type of hippocampal destruction. Extensive hippocampal lesions by aspiration resulted in a lack of spontaneous alternation and the absence of normal habituation in the activity cage, but did not affect running in the exercise wheel. Since the latter test is frequently used to measure drive (Strong, 1957), this type of hippocampal destruction would not appear to change the rat's drive

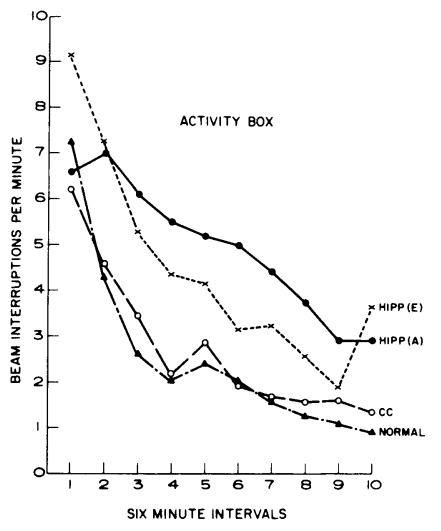

Fig. 2 Mean photocell beam interruptions in activity cage.

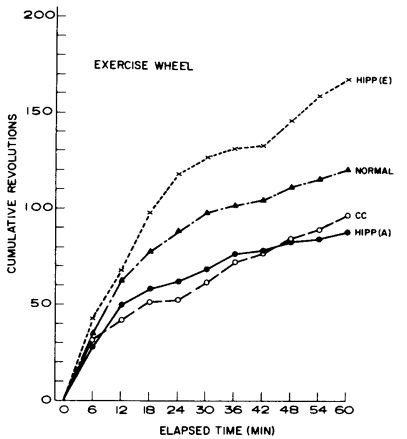

Fig. 3. Cumulative number of revolutions in exercise wheel.

level. These results are, however, consistent with the hypothesis that hippocampal destruction results in a lack of ability to inhibit responses, as both spontaneous alternation and cage habituation can be considered to involve inhibition of responses. On the other hand, the Elec. Hip. group behaved as if in a state of elevated drive: their activity curve appeared to be a multiple of those of the Neocort. and Normal groups. Furthermore, they ran more in the wheel than the other groups. The reason for the disparity in results between the two hippocampal groups cannot be determined at this time.

\section{References}

ISAACSON, R. L., DOUGLAS, R. J., \& MOORE, R. Y. The effect of radical hippocampal ablation on acquisition of avoidance response. J. comp. physiol. Psychol., 1961, 54, 625-628.

KAADA, B. R., RASMUSSEN, E. W., \& KVEIM, O. Effects of hippocampal lesions on maze learning and retention. Exp. Neurol., 1961, 3, 333-335.

RASMUSSEN, E. W., KAADA, B. R., \& BRULAND, H. Effects of neocortical and limbic lesions on the sex drive in rats. Act. physiol. Scand., 1960, 50, Suppl. 175, 126-127.

ROBERTS, W. W., DEMBER, W. N., \& BRODWICK, M. Alternation and exploration in rats with hippocampal lesions. J. comp. physiol. Psychol., 1962, 55, 695-700.

STRONG, P. N., JR. Activity in the white rat as a function of apparatus and hunger. J.comp. physiol. Psychol., 1957, 50, 596-600.

TEITELBAUM, H., \& MILNER, P. Activity changes following partial hippocampal lesions in rats. J.comp. physiol. Psychol., 1963, 56, 284-289.

\section{Note}

1. This research was supported in part by Grant DA-MD-49-193-63G75 from the Office of the Surgeon General, U. S. Army. 